\title{
INTRODUCTION
}

\section{The Politics of Noncompliance}

More than ten years after the collapse of Lehman Brothers in 2008, the European Union (EU) is still facing not one but multiple crises. The member states have managed to avert the breakdown of the euro. Yet Italy's expansionist budgetary policies could lead to its sovereign debt spin out of control and throw the eurozone into its next crisis. The historic influx of refugees into the EU, which brought the borderless Schengen area to the verge of collapse in 2016, may have subsided. But the EU has yet to agree on a common asylum and migration policy, by which all member states share responsibility rather than passing it on to a few. Even eastern enlargement, once celebrated as a success of the EU's transformative power, is called into question as Hungary and Poland, the former poster children of transition, contest the fundamental values of the EU. The Covid-19 pandemic, which struck Europe in early 2020, adds yet another crisis refueling and exacerbating the previous ones.

What the various crises have in common is that one of their main causes appears to be noncompliance with EU law. If Greece or Italy had complied with the legal rules governing the EU's common currency and the border-free Schengen area, they would not have piled up such record debts, nor would so many refugees and migrants have found their way into the EU but rather would have returned to their home countries. There is hardly any member state that has not violated the so-called convergence criteria, which are to keep in check state budgets. Likewise, virtually all member states have infringed on the EU's legal rules and procedures regulating the admission of refugees and asylum seekers. Finally, the EU initiated the Article 7 sanctioning procedures against Hungary 
and Poland for breaching fundamental values that are protected by Article 2 of the Treaty on European Union (TEU).

The extent to which member states have violated EU law during times of crises is exceptional. Rather than breaching selective legal obligations under EU law, Greece, Italy, Hungary, or Poland have gone against the core of norms and rules on which the euro, the border-free Schengen area, and the European Union as a polity are based. Moreover, noncompliance with EU law is usually about the scope of application. Member states usually contend that the law does not apply to the particular case at hand, or they disagree with the Commission as to what rule-consistent behavior entails. Italy, Greece, Hungary, and Poland, in contrast, have denied the validity of EU law, claiming that the EU has no authority to interfere with the sovereign right to spend their taxpayers' money, control their borders, and organize their political institutions.

At the same time, member state violations of euro and Schengen rules reflect those states' general noncompliance behavior. The laggards among the euro and the Schengen countries are also those who show the lowest levels of compliance with the more than thirty-four thousand pieces of EU legislation that regulate the quality of their drinking water, the equal treatment of men and women in the labor market, the admissibility of genetically modified food, or the rights of ethnic and sexual minorities. Whether it is their sovereign debt, the treatment of refugees, or the protection of wild birds, Greece and Italy outdo the other member states in their defiance of EU rules and regulations. They are joined by Portugal, France, and Spain. Denmark, Finland, Austria, the Netherlands, and Germany show greater respect for European asylum and refugee law, the Stability and Growth Pact, and the EU's environmental regulations. At the same time, there is significant variation within the two groups of compliance laggards and compliance leaders that defies any attempt to make noncompliance merely a "southern problem." Portugal and Spain have introduced comprehensive austerity measures and are praised by the European Commission for their reform efforts. Greece, by contrast, has only slowly been moving away from the edge of sovereign default. Italy used to show a strong commitment to reforms, but implementation is slow. The Commission opened an excessive-deficit procedure against Italy in November 2018. The populist government of the Five-Star Movement and the far-right League refused to back down in adjusting its budget plan for 2019, which violated EU fiscal rules by overspending on welfare. In that year, Italy's public debt ran at 131 percent of its gross domestic product (GDP) and was the second biggest in the eurozone after Greece. The EU's economic surveillance and disciplinary program could result in financial sanctions, amounting to fines of up to 0.2 percent of GDP and the suspension of some EU funds. After months of arm-twisting with the Commission, which saw Italy's credit ratings 
deteriorate, the Italian government finally settled at a compromise of 2.04 rather than 2.4 percent budget deficit.

France has largely managed to stay under the radar screen, despite posting the largest debt-to-GDP ratio among Europe's biggest economies and running a budget deficit of over 3 percent in 2019. Meanwhile, Denmark lives up to its reputation as the top of the class, whereas the UK and the Netherlands, which also belong to the group of compliance leaders, have been as reluctant as Spain, Italy, and Greece to abide with EU asylum and refugee law.

The euro, migration, and rule-of-law crises feature serious violations of EU law. This could lead to the conclusion that member states do not comply with EU law "when they view these rules as in conflict with ... their myopic self-interest" (Keohane 1984, 99). US president Donald Trump's “America first” policy would simply be symptomatic for states reasserting their national sovereignty against the liberal world order. The period after the end of the Cold War saw the rise of multilateral institutions at the global and regional level with more authority than ever before, reducing the relevance of the consent principle in interstate decision making (Lake 2009; Börzel 2013; Zürn 2018). For states that commit themselves to international law, the growing scope of international authority in the attempt to advance peace, prosperity, and justice at the global level further limits their freedom of action domestically. In the absence of compliance, however, international authority will be futile in helping to tackle global challenges such as climate change, the proliferation of weapons of mass destruction, or massive human rights violations. EU norms and rules are superior to national law, do not require ratification to take effect at the domestic level, and can rely on an independent court for their enforcement. Identifying conditions under which states break the law in such a highly legalized context contributes to our understanding of when international law impacts the behavior and the policies of states (Simmons 2009; Risse, Ropp, and Sikkink 2013; Haftel 2012). It also offers important insights as to why the rule-based international order has been under increasing pressure since the turn of the millennium (Ikenberry 2018; Alcaro 2018; Lake, Martin, and Risse, 2021).

As for the EU, policy makers and EU scholars have been claiming for decades the EU is suffering from a growing compliance problem, which they believe to be systemic or pathological to the EU (Krislov, Ehlermann, and Weiler 1986; Weiler 1988; Snyder 1993; Mendrinou 1996; Tallberg 2003; Cremona 2012; Commission of the European Communities 2011); the more political authority the EU acquires, the less member states obey its laws. This book argues the opposite. First, there is no evidence that the EU has a problem with noncompliance. If anything, the functioning of the Internal Market suggests that almost all member states comply with almost all EU law almost all the time (paraphrasing 
Henkin 1968,47$).{ }^{1}$ Second, the evidence that we have clearly indicates that noncompliance has been declining over the past twenty-five years. Violations of the euro and Schengen rules are extreme cases, which contradict this trend. Ever since the Maastricht Treaty sought to develop the Internal Market into a monetary, economic, and political union, noncompliance has decreased rather than increased, despite the substantive deepening and widening of European integration and a virtual doubling of the EU in size.

While not being indicative of a general compliance problem in the EU, the different extent to which member states have defied the EU's convergence criteria, Schengen rules, and fundamental values conforms to the general variation in member state noncompliance patterns. Moreover, as extreme cases, the euro, the migration, and the rule-of-law crises exemplify the role of politicization for explaining why some member states comply less with EU law than others do, and why noncompliance has declined since the 1990s. The different degree to which EU law spurs political conflict at the domestic level also helps to account for why noncompliance varies across policy sectors.

\section{Three Puzzles}

Noncompliance is defined as state behavior that is inconsistent with the obligations prescribed by domestic, international, or EU law (Young 1979, 104; Chayes, Chayes, and Mitchell 1998, 39; cf. Raustiala and Slaughter 2002). Placing the euro, the migration, and the rule-of-law crises into the broader picture of compliance in the EU gives rise to three puzzles that this book seeks to solve:

First, how do we account for the diverse patterns in member state noncompliance with EU law? Why does Eurosceptic Austria or the UK comply better with EU legal obligations than Europhile Italy, France, or Portugal? How is it that big and powerful Italy and France are almost as bad compliers as small Greece and Portugal? Why do centralized Greece and France have compliance records equally bad as those of regionalized Italy or Spain? As the book will show, none of the major compliance theories focusing on power, capacity, and legitimacy can fully capture these country-specific compliance patterns. They become even more puzzling when we bring eastern enlargement into the picture. Contrary to expectations of EU scholars and policy makers, the ten Central and Eastern European (CEE) countries, which joined the EU in the first decade of the 2000s, comply better on average than older member states whose domestic power and administrative capacity are equally limited and who show greater support for the EU. While the southern enlargement in the early 1980s had substantially 
increased noncompliance in the EU, eastern enlargement has had the opposite effect. This is hard to explain with standard accounts of the so-called southern problem (Pridham and Cini 1994) as the CEE countries equally struggle with authoritarian legacies and administrative capacities weakened by corruption and clientelism.

Second, noncompliance climbed steadily ever since the Commission began to report on violations of EU law in 1978. The trend reversed, however, in the early 1990s - despite an exponential growth in legal acts the EU had adopted in order to complete the Internal Market. Compliance research has been largely silent on temporal change focusing on explaining country variation. Existing compliance theories provide some potential explanations for why we might see a decline in noncompliance over time. Yet neither improvement in the EU's capacity to detect, punish, or manage violations of EU law, nor increasing socialization into EU law or changes in the public support for the EU, correlates with the decline in noncompliance since the 1990s.

Third, noncompliance with EU law does not only vary across time and member states. It also shows variation across policy sectors. All member states together infringe on EU law in some policy sectors more frequently than in others. Environment and Justice \& Home Affairs (JAIN) are the most noncompliant sectors, while Competition and Agriculture have given rise to far fewer problems. The limited attention compliance research has paid to the policy dimension may be related to the lack of some clear or intuitive patterns as we find them with regard to time (decline since 1994) and member states (North v. South, new v. old). What do Environment and JAIN have in common, and what separates the two sectors from Competition and Agriculture? Policy matters, but the literature offers hardly any explanation for why.

Taken together, the three puzzles form the main research question this book seeks to answer: How do we explain the variation in compliance patterns in the $\mathrm{EU}$, be it over time, between member states, or across policy sectors? Why has noncompliance in the EU decreased since the mid-1990s, despite a growing number of member states with weak compliance capacities and waning enthusiasm for European integration, and with EU legislation expanding in sectors that are particularly prone to noncompliance?

EU research has been rather eclectic in addressing noncompliance with EU law. It has identified a multitude of explanatory factors that provide a theoretical patchwork rather than a consistent theoretical approach (Toshkov 2010). This book develops a theory of compliance with international law that integrates major factors identified by various strands of the literature to account for variation across states, time, and sectors. 


\section{One Theory}

The literature on compliance has focused on three different sets of factors to explain state compliance with international norms and rules: the preferences of states, along with their power and their capacity to act upon these preferences (Chayes, Chayes, and Mitchell 1998; cf. Raustiala and Slaughter 2002; Simmons 1998; Tallberg 2002). On a theoretical level, preference-, power-, and capacitybased arguments tend to be treated as competing or alternative explanations of noncompliance (Chayes and Chayes 1993; Downs, Rocke, and Barsoom 1996; Checkel 2001). Yet, empirically, a growing number of studies find that all three sets of variables are causally relevant (Mbaye 2001; Linos 2007; Börzel et al. 2010). The book corroborates these findings. Rather than merely adding their explanatory power, it integrates different explanatory factors into a theoretically consistent model dubbed the power, capacity, and politicization model (PCP). Conceptualizing the politics of noncompliance as a two-stage game played by rational actors across two levels within an institutionalist setting allows us to specify how power and capacity of member states connect with EU institutions in influencing the noncompliance behavior of states. Moreover, introducing politicization, which crucially affects the ability of states to shape and take compliance costs, helps account for why member state noncompliance varies across time and sectors.

Noncompliance becomes an issue only in the case that states are not willing or not capable to cope with the costs. Costs arise when compliance with EU law requires institutional and behavioral changes at the domestic level. As rational actors, states have an incentive to reduce such costs in the adoption of EU law. They differ, however, in their ability to shape EU law according to their policy preferences. Likewise, states are not equally able to take compliance costs. The PCP model integrates the taking stage, at which EU law is implemented and enforced, and the shaping stage, at which EU law is negotiated and adopted. Moreover, the PCP model assumes that power, capacity, and politicization are key factors that affect the ability of states to shape and take EU law and its costs.

Power refers to the ability of states to pursue their preferences against resistance at the EU and the domestic level. In light of the highly legalized framework in which states cooperate in the EU and their democratic systems, state power is largely institutional. At the EU level, their votes in the Council and their contributions to the EU budget should enable member states to reduce compliance costs by shaping EU laws according to their policy preferences. Moreover, if they fail to do so, they can resist taking the costs at the domestic level because they can afford EU sanctions or deter EU enforcement authorities from imposing sanctions in the first place. 
Capacity relates to the resources member states are endowed with and the efficiency of their bureaucracies to use resources (staff, expertise) to shape EU law, on the one hand, and to change legal and administrative institutions, as well as the behavior of domestic actors targeted by EU law, on the other. The capacity to formulate a coherent bargaining position at the shaping stage and to bring together the public authorities with the competencies necessary to legally transpose, practically apply, and enforce EU law is not necessarily related to political and economic power a member state has in the EU. It allows small states, like the Netherlands or Denmark, to punch above their weight (Panke 2010a).

Politicization captures the extent to which compliance costs give rise to political conflict at the domestic level. It is not only a function of veto players, which have the institutional power to block compliance because they are not willing to incur the costs. Domestic actors have to be aware of the costs, and they have to care about them, being willing to politically mobilize against their governments imposing these costs on them. The compliance literature has largely neglected the public visibility of international and EU law and the public sensitivity to its costs. A higher propensity of politicization in the taking of EU law at the domestic level can increase the ability of a government to negotiate for less costly outcomes at the EU level. At the same time, politicization can seriously constrain the ability of a government to introduce the domestic changes necessary to achieve compliance.

The PCP model expects small member states like Denmark with weak voting and budget power, an efficient bureaucracy, and a Eurosceptic public, to be the best compliers. The likely domestic resistance against high compliance costs allows Denmark to shape EU laws despite its limited power. Should it fail at shaping, it still has the capacity to comply with costly EU laws and not enough power to resist enforcement power. On the other end of the spectrum, we find big countries, such as Italy and France, which have strong political and economic weight in the EU but inefficient bureaucracies and citizens who support the EU. They are less able to shape EU policies to minimize compliance costs. However, they have the power to resist enforcement pressure when their low capacity prevents them from taking the costs. As a result, France and Italy, as two of the largest EU economies, are as bad compliers as Greece, which has always been the poorest member state in the EU-15; while the UK and Denmark, as the two most Eurosceptic member states, are more compliant than Germany. Politicization also helps explain the counterintuitive finding that Eurosceptic member states are better compliers than their Europhile counterparts. Lower public support for the EU renders the politicization of compliance costs more likely. Governments can use their Eurosceptic publics to tie their hands (Putnam 1988) at the shaping stage, bargaining for EU laws that are closer to their policy preferences and entail lower costs. 
By incorporating EU-level factors that are not country specific, the PCP model can also account for the time trend in declining noncompliance since the completion of the Internal Market. EU law has become less costly to comply with over the past twenty-five years, as it tends to amend existing rather than introduce new legislation. Amending legislation is less complex and requires fewer institutional and behavioral changes at the domestic level. Moreover, compliance costs are less likely to be politicized in the member states since large parts of EU law have been adopted and implemented with no parliamentary involvement. Finally, noncompliance is higher in sectors harmonizing national regulations, because the compliance costs of market-correcting policy are more likely to become politicized.

The PCP model offers four major benefits. First, it pulls together diverse strands of existing theory and empirical research on noncompliance in international relations (IR) and EU studies by integrating the bargaining (shaping) and the implementation and enforcement (taking) stages of EU law making. Drawing on the principal components of major IR approaches allows the PCP model to organize the multitude of explanatory factors empirically analyzed in EU research into three distinct theoretical concepts (power, capacity, politicization), thereby reducing the eclecticism and complexity of many approaches. So do the empirical testing of alternative conceptualizations and the operationalizations of power, capacity, and politicization.

Second, the PCP model moves beyond country variation. Both IR and EU research focus on explaining why some states comply less than others. EU scholars tend to assume that the EU has a growing compliance problem and argue about how to measure it (cf. Börzel 2001b). Likewise, IR scholars have debated whether compliance with international law has really deteriorated or to what extent this is an information effect (Clark and Sikkink 2013). Some EU studies have ventured into sector variation but identify selected variables that are related to individual legal acts rather than policy sectors. IR research has been reluctant to compare international institutions with regard to noncompliance because of the great differences between them.

Third, systematically exploring temporal and sectoral variation allows us to theorize how EU institutions and sector characteristics affect compliance costs and the power and capacity of states to shape and take them, adding politicization, which has been largely neglected in compliance research. The PCP model thereby provides a comprehensive explanation for why some member states comply less than others, why noncompliance in the EU has been declining, and why some policy sectors are particularly prone to noncompliance.

Fourth, since the PCP model draws on principal components of IR theories, it also travels outside the EU. International institutions, which do not pool and delegate political authority to the extent the EU does, still have an effect, albeit 
weaker, on compliance costs and the ability of states to shape and take them. These effects should also vary depending on the policy type and the regulatory logic of the issue area international institutions are tasked to deal with.

\section{One Data Set}

For the empirical analysis, the book draws on the European Commission's own infringement database, from which I received a data set covering the period of 1978 until 1999. I have been constantly updating the data set over the past twenty years. Unlike the data publicly accessible, the Berlin Infringement Database (BID) contains detailed information on the more than 13,300 violations of EU law the EU officially recorded between 1978 and 2019 (March). As the most comprehensive database on noncompliance with EU law, it allows for analyzing variation across time, member states, policy sectors, type of legal act, and type of violation. It encompasses all the cases in which the European Commission determined a violation of EU law. This may only cover the tip of the iceberg of noncompliance in the EU, and we have no way of knowing how big the iceberg is. Unlike alternative measures of noncompliance, however, infringement proceedings are less prone to bias and cover all possible types of violations of EU law, not only the transposition of directives into national law. While the BID does not allow us to measure the size of the iceberg, it includes all those cases that lie at its core and are central for the functioning of the EU.

\section{Organization of the Book}

Chapter 1 maps the variation in noncompliance across countries, time, and sectors. I outline the three puzzles the empirical chapters will explore in more detail. First, I tackle the methodological challenges of measuring noncompliance and introduce the BID. Weighing the strengths and weaknesses of the different indicators developed in the literature, I justify my choice of using the EU's official infringement proceeding to measure my dependent variable. Reasoned opinions are the first official stage of the legal action the European Commission can bring against the member states for violating EU law. Some caveats notwithstanding, I argue that they are the most comprehensive and reliable measurement of noncompliance with EU law. The chapter concludes with placing infringements into the wider context of noncompliance with EU law outside the Internal Market. I point to the risks of the EU trying to enforce compliance with its fundamental values and redistributive decisions, such as the relocation of refugees, the same way it does with regulatory policy. 
Chapter 2 develops the PCP model that brings together power, capacity, and politicization in a theoretically consistent way. I start by integrating power and capacity within a rational institutionalist framework that conceptualizes noncompliance as a two-stage game played across two levels. This allows me to introduce politicization as a third principal component. The PCP model starts from the assumption that the costs of compliance determine the choice of member states to comply or not comply with EU laws. At the EU level, member states use their capacity and power to shape EU laws to make them less costly for their domestic constituencies. Member states have an advantage at the shaping stage when they can tie their hands to domestic constituencies that are likely to politicize EU law in the implementation at the taking stage. Capacity renders member states better shapers. It also enables them to take compliance costs in the implementation of EU law at the domestic level. Power, in contrast, allows member states to resist compliance with costly laws at the taking stage. Power, capacity, and politicization are country-specific variables that are rather stable across time and policy sectors. To account for temporal and sectoral variation, the PCP model brings in EU institutions. These institutions mitigate member states' power and enhance their capacity. EU decision-making rules at the shaping stage also influence the propensity of domestic politicization at the taking stage. Parliamentary involvement at the EU and the domestic level increases the public visibility of costly EU laws. Moreover, the compliance costs of EU laws and their propensity of politicization differ across policy sectors. Regulatory policy that aims at protecting citizens against market failure by harmonizing social and environmental standards incurs higher costs that are more likely to be politicized at the domestic level. Based on these propositions, I formulate expectations on which member states are more likely to violate EU law, on when noncompliance is likely to subside over time, and on which sectors of EU law are more prone to noncompliance.

Chapter 3 solves the first puzzle of the book related to the country variation: Why do some member states comply less than others? I argue that member state noncompliance is neither a purely southern nor an eastern problem. Neither the power nor the capacity nor the propensity of politicization varies systematically between the advanced industrial democracies forming the northern and western core of Europe, and its southern and eastern European periphery. Member state noncompliance in a deepened and widened $\mathrm{EU}$ is best explained by the combination of power, capacity, and politicization. Denmark and the UK are such good compliers not only because they have efficient bureaucracies; their Eurosceptic publics allow them to shape EU policies according to their preferences, reducing costs or seeking an opt-out. If they fail, both have the capacity to comply with costly EU law. Denmark's performance is even more exemplary, because, unlike the UK, it lacks the power to resist enforcement pressures. Europhile Italy and 
Greece are such bad compliers because they lack the capacity both to reduce compliance costs by "uploading" their policy preferences to the EU level and to deal with the costs. What makes Italy the ultimate No. 1 noncomplier of the EU is its power to resist compliance. Unlike small and poor Greece, it can afford sanctioning costs.

Chapter 4 explains the second puzzle of the book regarding temporal variation: Why has noncompliance declined since the 1990s? Although compliance research has largely neglected time, many students of the EU assume that noncompliance has become worse amid a growing body of EU law and a rising number of member states that can violate them. Yet, while we have no data to evaluate how big the absolute noncompliance problem of the EU has been, I can show that it has not been growing. On the contrary, since the mid-1990s, we can observe a negative trend, which is driven by the more effective transposition of EU directives. In the absence of established explanations for temporal variation, the second part of the chapter uses the EU-level factors identified by the PCP model as affecting compliance costs and their politicization to explain why noncompliance has been declining. The decline in noncompliance is a secular trend that is related to changes in the nature of EU law. EU directives amend existing rather than set new legislation. Their adoption is (therefore) delegated to the Commission. Delegated legislation is less costly and less demanding on the capacity of the member states. I demonstrate that delegation has depoliticized EU law, despite the empowerment of the European Parliament and national legislatures in EU affairs. Policy without politics, however, comes at a price-it has fueled the politicization of the EU as a polity, undermining its democratic accountability.

Chapter 5 accounts for the third puzzle concerning policy variation: Why are some sectors more prone to noncompliance? I start with showing that to the extent the EU has a noncompliance problem, it is concentrated in four policy sectors. Following Theodore Lowi's famous dictum that policy determines politics, I use the PCP model to develop one of the first attempts to theorize sector-related noncompliance in the EU. I show that regulatory policy produces higher compliance costs than nonregulatory policy. (Re-)distributive policy is also costly, but the costs arise in decision making, not in implementation. Regulatory policy is particularly costly if it is market correcting rather than market making. Harmonizing national standards to protect EU citizens against failures of the Internal Market requires institutional and behavioral changes in the member states, which are costly and more likely to be politicized. The chapter concludes by arguing that the rise of populism in Europe renders noncompliance with regulatory policy even more costly, which has serious implications for the EU as a regulatory polity, particularly if it continues to transform redistributive issues into regulatory problems as it has done in the euro and migration crises. 
The conclusion revisits the PCP model in light of the empirical findings of chapters $3-5$. These findings allowed us to refine the model by specifying which factors affect the costs of compliance, their politicization, and the power and capacity of the member states to shape and take these costs. First, the most important EU-level factors lie in the nature of EU law. New legislation is costlier and more likely to be politicized because its adoption is not delegated to the Commission. Second, when it comes to country-related variables, it is neither the voting nor the budgetary power of member states but the Euroscepticism of their publics that matters for their ability to shape compliance costs. Governments tying their hands to their Eurosceptic publics account for the counterintuitive finding that greater public support for the EU results in more, not less, noncompliance. Third, power still matters for the taking of costly EU laws. Member states rely on their political and economic weight to resist compliance costs rather than to deter the European Commission from enforcing compliance. Fourth, rather than resources per se, the efficiency of national bureaucracies in using existing resources defines the capacity of member states to effectively shape and take EU laws and cope with their costs.

The concluding chapter also discusses the generalizability of the PCP model with regard to other regional and international organizations, particularly in light of the extraordinary degree to which authority is pooled and delegated in the EU. Since the PCP model draws on principal components of IR theory, the book offers some important contributions to the broader research on compliance with international law. It shows that power and capacity are not alternative or competing explanations of noncompliance but need to be combined to account for the empirical variation across countries, time, and policy sectors. Moreover, the politicization of international institutions and their decisions at the domestic level has a major influence on noncompliance that has been neglected in the literature so far. Finally, the nature of international law, rather than the rules and procedures by which it is adopted and enforced, deserves greater attention.

The chapter concludes by considering the implications of the PCP model of noncompliance for the effectiveness and legitimacy of the EU and international governance more broadly. If the costs of international regulatory policy, reaching from trade, to climate change, to nuclear arms control, become increasingly politicized at the domestic level, this does not only increase the risks of noncompliance. It also challenges the capacity and authority of international institutions to set such regulations in the first place. The rise of nationalist populism exemplified by Brexit, the democratic backsliding of Hungary and Poland, and the election of Donald Trump as US president show the limits of regulatory governance beyond the state. 